\title{
RESÍDUOS DA CONSTRUÇÃO CIVIL: O CASO DE UMA CONSTRUTORA NO MUNICÍPIO DE PARAGOMINAS - PA
}

\author{
Amanda Campos Pinto; Taianaacã Fernandes Brandão Santos; Antônio Pereira Júnior \\ DOI: $10.4322 / 978-85-455202-1-4-06$ \\ INTRODUÇÃO
}

No Brasil a geração contínua e crescente de Resíduo de Construção Civil (RCC), entulho, composto por papel, papelão, concreto, pedra, gesso dentre outros, está diretamente ligada ao elevado desperdício de materiais na realização de empreendimentos da construção civil. Estima-se que, para cada tonelada de lixo urbano recolhido, são coletadas duas toneladas de entulho originado por esse setor.

Esse dado alarmante revela a necessidade de políticas de controle, coleta, transporte e disposição final e que viabilizem o emprego desses resíduos de construção e demolição reciclados como matéria-prima na confecção de novos materiais (DIAS, 2007). Em estudo realizado no município de Brasília (GEHLEN, 2008), sobre a construção da sustentabilidade em canteiros de obras, revela que $82 \%$ dos profissionais ligados ao setor da construção civil, detém conhecimento acerca do que é desenvolvimento sustentável, porém apenas $9 \%$ colocam em prática tal conhecimento.

A construção sustentável tem como objetivo a harmonia entre o ser humano e o meio ambiente, gerando considerável redução na degradação, através do uso de materiais reciclados, matérias-primas renováveis, resíduos, ou materiais sem componentes tóxicos e tecnologias que não causem danos ao Meio Ambiente, vindo a se tornar uma construção ecologicamente correta que visa sua auto sustentabilidade (BVSDE, 2008).

Para estabelecer diretrizes sobre esse assunto, o Conselho Nacional do Meio Ambiente (CONAMA) publicou a Resolução no 307/2002 (BRASIL, 2002) que estabelece diretrizes, critérios e procedimentos para um novo sistema de gestão, obrigando os geradores a reduzir, reciclar, reutilizar, tratar e, por último, dar uma destinação adequada para os RCC's, não eximindo o gerador da responsabilidade, caso tenha contratado uma empresa terceirizada, para fazer o serviço e ela não possua local licenciado para disposição desse tipo de resíduo.

Essa Norma foi apoiada mais ainda a partir da promulgação da Política Nacional de Resíduos Sólidos (PNRS), instituída pela Lei n ${ }^{\circ}$ 12.305/2010 - Decreto nº 7.404 (BRASIL, 2010), estabeleceu como princípios o Plano Municipal de Gestão Integrada de Resíduos Sólidos (PMGIRS), onde nele deve estar implementada a gestão dos resíduos da construção civil, a valorização dos resíduos, a produção e consumo sustentável, sendo os recursos, financiamentos ou incentivos da União só repassados aos municípios que possuírem os respectivos planos. Tendo ambas que se adaptarem de modo a assegurar que os resíduos tenham destinação ambientalmente adequada.

Enfim, o correto gerenciamento do resíduos de construção civil em um canteiro de obras deve ser objeto de monitoramento constante, e isso justifica essa pesquisa, além de incrementar a relevância dela e, com isso, contribuir para que o objetivo, que é analisar a realização do processo de gerenciamento de resíduos de construção civil (RCC) pela empresa x na etapa de fundação do processo de construção no canteiro de obras. 


\section{REVISÃO DA LITERATURA}

\section{HISTÓRIA DA CONSTRUÇÃO CIVIL NO BRASIL}

A precursora da engenharia civil no Brasil foi criada em 1792 pelo vice-Rei D. Luiz de Castro, e era denominada, Real Academia de Artilharia, Fortificação e Desenho. A primeira escola de engenharia brasileira foi criada em 4 de dezembro de 1810 pelo então futuro Rei D. João VI, assinando a lei que criaria a Academia Real Militar do Rio de Janeiro, onde nesse período quem executava tais ocupações era chamado de engenheiro militar, mesmo não seguindo a carreira militar. No ano de 1858 foi criado o curso de engenharia civil, ministrados às pessoas que não exerciam a carreira militar, ou seja, aos civis (UFRJ, 2007).

Quanto a esses fatos, estudo de) afirma que a engenharia civil no Brasil iniciou as atividades de forma não regulamentada no período colonial de fortificações e igrejas. Durante esse período agiam dois grupos de profissionais na área de engenharia: os oficiais Engenheiros e os Mestres Pedreiros, onde os primeiros eram oficiais do exército brasileiro, com a finalidade principal de executar obras de engenharia e os Mestres projetavam e construíam as edificações em geral, sendo seus conhecimentos passados de geração a geração (RIBEIRO 2011; TÉSIO, 2007).

Em relação ao processo evolutivo desse setor industrial, percebe-se que no século XX, mais precisamente em 1940, durante o governo de Getúlio Vargas, houve o primeiro grande crescimento na construção civil brasileira, sendo ela considerada a década auge da construção civil no Brasil devido ao forte investimento estatal realizado nesse setor. Na década de 1950 perdeu incentivos do Estado, sendo financiada pela iniciativa privada. Durante o regime militar, na década de 1970 a presença estatal voltou a ocorrer com mais força, deixando a iniciativa privada somente com os prédios de apartamentos e escritórios comerciais (CARDOSO, 2013).

Cardoso (2013) ainda enfatiza que, na década de 1980, o capital privado retorna na construção civil e já começava a existir uma preocupação maior com a qualidade do produto final, fazendo assim com que as construtoras investissem mais em mão-de-obra qualificada de suas equipes.

\section{IMPORTANCIA DA CONSTRUÇÃO CIVIL NO BRASIL}

O setor da construção civil é composto por uma enorme quantidade de atividades, devido a sua magnitude é chamado de macro complexo da construção, que é um conjunto de atividades econômicas, diferentes e interligadas umas às outras. É importante ressaltar que a construção tem um papel fundamental para o progresso nacional, uma vez que edifica obras que sustentam o progresso, gera empregos diretos e indiretos, renda para a população e aprimoram recursos tecnológicos inovadores (ERDEI, 2011).

A construção civil no Brasil é a área que mais possui capacidade de aumentar a taxa de emprego, de produto e de renda, tanto a curto ou médio prazo, uma vez que sua capacidade de absorver mão-de-obra é enorme, fazendo com que as taxas de desemprego caiam em momentos em que a economia não anda bem. Mas para que isso ocorra, é necessário que haja incentivos governamentais que elevem a demanda por produção e, em decorrência desse fato, os produtos e serviços que estão integrados à construção civil aumentem. São produtos vendidos em larga escala como parafusos, pedras, areia, tintas dentre outras, que fazem com que as empresas produzam mais, gerando emprego e oportunidades (MAZANTO, 2014).

A importância da construção civil tem um papel fundamental na elevação da capacidade de produção da economia em geral. Apesar de ela não produzir maquinas e equipamentos e nem elevar diretamente a formação técnica das pessoas, é ela que constrói prédios, estradas, portos, faculdades e uma infinidade de outros tipos de construção que aumentam direta ou indiretamente a capacidade de produção da economia. Tudo que é criado por esse setor da economia possui um proveito muito significativo para a economia e para sociedade, pode-se até discutir eventuais problemas, 
notadamente quando envolvem pessoas do setor público, porém não se deve jamais duvidar da importância da construção civil para a economia brasileira (CASTRO, 2012).

\section{RESÍDUOS SÓLIDOS}

\section{ETIMOLOGIA DA PALAVRA E O CONCEITO DO TERMO.}

Resíduo sólido deriva do Latim residuu, que significa o que sobra de determinada substância. A palavra sólida é incorporada para diferenciar de líquidos e gases. A Norma Brasileira de Regulamentação de no 10004 (ABNT, 2004), apresenta o seguinte conceito para resíduos sólidos:

resíduos nos estados sólido e semissólido, que resultam de atividades de origem industrial, doméstica, hospitalar, comercial, agrícola, de serviços e de varrição. ficam incluídos nesta definição os lodos provenientes de sistemas de tratamento de água, aqueles gerados em equipamentos e instalações de controle de poluição, bem como determinados líquidos cujas particularidades tornem inviável o seu lançamento na rede pública de esgotos ou corpos de água, ou exijam para isso soluções técnica e economicamente inviáveis em face à melhor tecnologia disponível (ABNT, 2004).

Desde a segunda revolução industrial, no final do século XIX, mais precisamente em 1870, a capacidade industrial aumentou, a produção das indústrias obteve um grande desenvolvimento, as inovações tecnológicas tornaram os bens de consumo artigos "descartáveis", e o consumismo frenético da geração atual, são fatores que mais contribuem para produção de resíduos, e como ônus de tal desenvolvimento, a geração de resíduo só aumentou e poucas ações estão sendo realizadas para oferecer a destinação mais adequada para tais resíduos produzidos (SOUSA, 2014).

\section{CLASSIFICAÇÃO}

Para a Associação Brasileira de Normas Técnicas (ABNT, 2004) e a Comissão Nacional do Meio Ambiente (CONAMA), os resíduos sólidos podem ser classificados da seguinte forma:

a) Resíduos classe I - perigosos: são aqueles que apresentam periculosidade ou características de inflamabilidade, corrosividade, reatividade, toxicidade ou patogenicidade, ou constem nos anexos A e B da referida norma.

b) Resíduos classe II A - não-inertes: são aqueles que não se enquadram nas classificações de resíduos classe I ou resíduos classe II B, podendo ter propriedades de biodegrabilidade, combustibilidade ou solubilidade em água.

c) Resíduos classe II B - inertes: são aqueles que, quando amostrados de uma forma representativa e submetidos a um contato dinâmico e estático com água destilada ou desionizada, à temperatura do ar ambiente, não tiverem nenhum de seus constituintes solubilizados a concentrações superiores aos padrões de potabilidade de água, executando-se aspecto, cor, turbidez, dureza e sabor.

\section{RESÍDUOS DE CONSTRUÇÃO CIVIL}

\section{POLÍTICA NACIONAL DE RESÍDUOS SÓLIDOS (PNRS)}

A PNRS tem como objetivo a não geração, redução, reutilização e tratamento de resíduos sólidos, bem como a destinação final ambientalmente adequada dos rejeitos. Redução do uso dos recursos naturais (Ex.: água e energia) no processo de produção de novos produtos, intensificar ações 
de educação ambiental, aumentar a reciclagem no país, promover a inclusão social, a geração de emprego e renda de catadores de materiais recicláveis (SENAC, 2009).

Essa política contempla pontos fundamentais para uma efetiva gestão dos Resíduos Sólidos (RS) através do desenvolvimento de Planos de Gestão dos Resíduos Sólidos na esfera federal, estadual e municipal, e da atribuição de responsabilidade a todos os envolvidos no ciclo produtivo.

Nesse contexto, verifica-se que, no artigo 20 para o RCC, obriga a elaboração de um Plano de Gerenciamento de Resíduos Sólidos (PGRS) para esse tipo de resíduo especifico, estando assim, duplamente e legalmente cobrados em relação aos Planos de Gerenciamento desses resíduos, por meio da PNRS e da Resolução CONAMA 307/2002 (FERNANDES, 2013).

Em relação às responsabilidades estabelecidas pela PNRS, às três esferas legislativas são o governo federal, que exerce papel essencial, uma vez que dele depende a coordenação, regulamentação e financiamento das ações que são adotadas em nível local. Os governos municipais responsáveis diretamente pela gestão de resíduos que necessitam lidar com suas restrições orçamentárias e técnicas, além de investir na gestão regional consorciada o que garante a implementação do plano e sua viabilidade financeira. E o setor privado, onde deve ser economicamente atrativo o investimento na gestão de Resíduos Sólidos Urbanos (RSU), com alternativas ambientais e socioambientais corretas (OLIVEIRA, 2012)

\section{CONSELHO NACIONAL DO MEIO AMBIENTE (CONAMA)}

O Conselho Nacional do Meio Ambiente (CONAMA), Resolução no 307/02 estabelece diretrizes, critério e procedimentos para gestão dos RCC, por meio do gerenciamento desses resíduos através primeiramente da não geração e secundariamente a redução, reutilização, reciclagem, o tratamento adequado dos resíduos sólidos e a disposição final ambientalmente adequada dos rejeitos. Tal resolução também determina que os geradores desses resíduos sejam responsáveis por eles e que a gestão integrada desses resíduos deverá proporcionar benefícios de ordem social, econômico e ambiental (FERNANDES, 2013).

De acordo com os artigos 5 e 9 dessa Resolução, é obrigatório a elaboração do Plano Integrado de Gerenciamento de Resíduos da Construção Civil (PIGRCC) pelos municípios contendo o Programa Municipal de Gerenciamento de Resíduos da Construção Civil (PMGRCC) e os Projetos de Gerenciamento de Resíduos da Construção Civil (PGRCC). Sendo o PMGRCC responsável por orientar os pequenos geradores nas suas atividades e o PGRCC deve ser desenvolvidos pelos grandes geradores e precisarão conter as etapas de caracterização do resíduo, triagem, acondicionamento, transporte e destinação (PANDOLFO, 2012).

\section{DEFINIÇÃO}

Segundo a Resolução 307 do Conselho Nacional do Meio Ambiente-(BRASIL, 2002), os resíduos de construção civil são:

Os provenientes de construções, reformas, reparos e demolições de obras de construção civil, e os resultantes da preparação e da escavação de terrenos, tais como: tijolos, blocos cerâmicos, concreto em geral, solos, rochas, metais, resinas, colas, tintas, madeiras e compensados, forros, argamassa, telhas, pavimento asfáltico, vidros, plásticos, tubulações, fiação elétrica etc., comumente chamados de entulhos de obras, caliças ou metralha (BRASIL, 2002). 


\section{CLASSIFICAÇÃO}

Para o Conselho Nacional do Meio Ambiente (CONAMA), os resíduos devem ser classificados a partir da Resolução no 307 (BRASIL, 2002), os RCC podem ser classificados da seguinte forma:

Classe A - resíduos reutilizáveis ou recicláveis, como agregados, tijolos, blocos, telhas, placas de revestimento, argamassas, concretos, tubos, meio-fio, solos de terraplanagem, etc.

Classe B - resíduos recicláveis para outras destinações, tais como plásticos, papel/papelão, metais, madeiras, etc.

Classe C - resíduos ainda sem tecnologias ou aplicações economicamente viáveis para a sua reciclagem/recuperação.

Classe D - perigosos, como tintas, solventes, óleos e outros, ou aqueles contaminados.

\section{GERAÇÃO}

No Brasil, a geração per capita de RCC é de ordem de $500 \mathrm{~kg} / \mathrm{hab}$./ano (ÂNGULO et al., 2003). Isso significa uma geração de 68,5 milhões de toneladas por ano de RCC. No quadro da gestão ambiental urbana, o gerenciamento dos resíduos sólidos é um dos mais graves e difíceis de trabalhar. No nosso país, tal fato decorre de vários fatores tais como: Crescimento da população urbana, aumento da capacidade produtiva, especialmente na indústria da construção civil, aumento e diversificação do consumo e introdução de novos materiais (Tabela 1).

Tabela 1- Estimativa da geração de RCC em alguns municípios brasileiros.

\begin{tabular}{|c|c|c|c|c|c|}
\hline Municipios & $\begin{array}{l}\text { População } \\
\text { (1 mil) }\end{array}$ & $\begin{array}{l}\text { Massa gerada } \\
\text { (tddia) }\end{array}$ & $\begin{array}{l}\text { Volume gerado } \\
\left.\text { ( } \mathrm{m}^{3} / \mathrm{dia}\right)\end{array}$ & $\begin{array}{l}\text { Geração per capita } \\
\text { (Ihabitante ao dia) }\end{array}$ & Fonte \\
\hline Catanduva-SP & 112 & 150 & 125 & 1,11 & \multirow{2}{*}{ Marques Neto (2009) } \\
\hline Fernandópolis-SP & 65 & 82 & 68 & 1,05 & \\
\hline Ituitaba-MG & 89 & 67 & 61 & 0,68 & Tavares (2007) \\
\hline Lavras-MG & 87 & 56 & 47 & 0,57 & Troca (2006) \\
\hline Macedônia-SP & 4 & 6 & 5 & 1,25 & \multirow{4}{*}{ Marques Neto (2009) } \\
\hline Marissol-SP & 53 & 77 & 64 & 1,21 & \\
\hline Olimpia-SP & 50 & 76 & 63 & 1,26 & \\
\hline Paulo de Faria-SP & 9 & 17 & 14 & 1,56 & \\
\hline Presidente Prudente-SP & 202 & 342 & 263 & 1,30 & Pinto (2008) \\
\hline Santa Maria-RS & 242 & 127 & 106 & 0,43 & Piovesan Júnior (2007) \\
\hline Santos-SP & 418 & 434 & 362 & 0,86 & Castro (2003) \\
\hline São Carlos-SP & 197 & 381 & 635 & 3,22 & Marques Neto (2003) \\
\hline São José do Rio Preto-SP & 413 & 1267 & 1056 & 2,56 & Marques Neto (2009) \\
\hline
\end{tabular}

Fonte: Adaptado de Córdoba (2010), IPEA (2012).

Na indústria da construção civil, os resíduos são sempre gerados dentro dos próprios processos da obra. Pode-se dizer que há basicamente três fases nas quais o RCC é gerado: fase da construção, fase de manutenção ou reformas e a fase de demolição (HOOD, 2006). Quanto aos tipos de resíduos gerados, verifica-se que na fase de demolição há geração de: concretos, argamassa, rochas, solos e cerâmicas. Eles são uns dos grandes responsáveis pelo esgotamento de áreas de aterro das grandes e medias cidades, já que eles representam mais de 50\% dos RSU (PAYERAS, 2005). 
Porém, tal geração pode estar relacionada com as obras de infraestrutura urbana, novas edificações, ampliação, reforma e demolição de edificação, de responsabilidade de poder público e iniciativa privada, que são os responsáveis pelo grande crescimento dos resíduos de construção e demolição (MMA, 2005).No país, estima-se que é gerado anualmente algo em torno de 68,5 x 106 toneladas de entulho. Outro fator a se destacar é a extração desnecessária de recursos naturais que poderiam ser evitados com a reutilização e/ou reciclagem do entulho gerado. Portanto se os resíduos oriundos do RCC fossem segregados na hora do descarte poderia haver um aproveitamento maior, diminuindo assim a extração dos recursos naturais e aumentando a vida útil dos aterros sanitários (FRAGA, 2006).

\section{LOGÍSTICA}

A cadeia logística desse resíduo pode ser dividida em dois subsistemas distintos, e os mesmos merecem tratamentos específicos, visto a existência de diferentes participantes e etapas em cada um deles (PUCCI, 2006). Esses subsistemas são divididos da seguinte forma:

- $\quad$ SUBSISTEMA INTERNO À OBRA: que trata do resíduo gerado por uma tarefa específica, sua segregação, seu acondicionamento no local da tarefa, seu transporte até o local de armazenamento da obra e armazenamento até sua retirada.

- $\quad$ SUBSISTEMA EXTERNO À OBRA: compreendendo as etapas de armazenagem do resíduo para retirada, o transporte e sua deposição final, sendo que esse subsistema se apresenta muito mais complexo que o primeiro, visto que as responsabilidades por cada etapa pertencem a diferentes interlocutores.

\section{DISPOSIÇÃO FINAL}

Em relação à disposição final do RCC, se depositado inadequadamente o concreto pode contaminar águas do subsolo, não devendo assim, ser considerado um material inerte. Sugere, também, que os resíduos de construção sejam classificados como classe II A e recomendam a reciclagem como uma opção para seu reaproveitamento (JADOVSKI, 2005).

Mas a Resolução CONAMA n 307/2002 (BRASIL, 2002) estabelece que esses resíduos não podem ser dispostos em aterros de resíduos sólidos domiciliares ou em bota-fora. Também estabelece que a competência para o gerenciamento dos mesmos fica sob responsabilidade dos governos municipais (AZEVEDO; KIPERSTOK; MORAES, 2006).

Porém, estudos efetuado sobre a disposíção final desse tipo de resíduo (OLIVEIRA; MENDES, 2008) concluíram que há custos elevados por parte da Administração Pública na limpeza e remoção desses resíduos de locais inadequados, bem como da construção de um local apropriado para receber os mesmos, esse é um dos grandes problemas enfrentados pelos governantes, o que gera um ciclo vicioso de disposição inadequada e remoção dos mesmos pelas companhias de limpeza pública ou terceirizadas.

Contudo, se o entulho for empregado como matéria-prima ou agregado, ele pode deixar de ser um problema, e tornar-se uma saída para a escassez de materiais granulares (diminuindo o consumo de insumos da construção civil oriundo de processo de britagem de rochas, britas e areia artificial) capazes de ser utilizados para tal fim. O emprego desse resíduo contribuiria igualmente de forma positiva para a diminuição do consumo de insumos da construção civil oriundo de processo de britagem de rochas, britas e areia artificial, uma importante ferramenta no combate a degradação ambiental (BARBOSA, 2012).

Em relação aos RCC's, sabe-se que eles são os grandes responsáveis pelo esgotamento de áreas de aterros em cidades de grande e médio porte, já que correspondem a mais de $50 \%$ dos resíduos sólidos urbanos. Eles também originam alto custo ambiental e socioeconômico nestas cidades em 
decorrência das deposições irregulares. Esses entulhos apresentam como principal característica a predominância de material inerte, passiveis de serem reaproveitados (PAYERAS, 2005).

Mas, a facilidade de transferir a responsabilidades dos resíduos gerados da obra por meio de empresas especializadas, leva o construtor a falsa impressão de ter solucionado o impacto ambiental gerado, já que o serviço está sendo pago. A corresponsabilidade, apesar de ser abordada na CONAMA 307/2002, não é fiscalizada ou cobrada por órgãos fiscais competentes, habitualmente, verificado no dia-a-dia dos canteiros de obra, simplesmente são dados documentos informando o lugar onde foram postos o resíduo e a identificação das empresas transportadoras à prática dessa atividade (LOPES; CASAGRANDE JUNIOR, 2009).

As disposições irregulares normalmente são resultados de pequenas obras ou reformas realizadas pelas camadas da população urbana mais carente de recursos, normalmente por processo de autoconstrução, porque não dispõe de recursos financeiros para a contratação das empresas coletoras, Esse problema é mais comum em bairros periféricos de baixa renda, onde o número de áreas livres é maior (PINTO; GONZÁLES, 2005).

Quanto às disposições irregulares dos resíduos da construção civil no ambiente urbano, podese concluir que elas são o resultado da inexistência de soluções eficazes para a captação destes resíduos, da falta de uma fiscalização eficiente e, até mesmo, da falta de uma conscientização da população quanto aos danos provocados pelos descartes indiscriminados do entulho em locais inadequados. As disposições irregulares dos resíduos da construção civil no meio ambiente urbano geram problemas de ordem ambiental, social e econômica, pois comprometem o meio ambiente, promovem a redução da qualidade de vida da população e aumentam os custos com a limpeza urbana (AQUINO, 2004).

\section{DESPERDÍCIO E RECICLAGEM}

Quanto ao desperdício de materiais na realização de empreendimentos, no Brasil, houve uma geração continua e crescente de RCC. Estima-se, que para cada tonelada de lixo recolhido, são coletadas duas toneladas de entulho gerado do setor de construção civil. Esse dado alarmante mostra a necessidade de políticas de controle, coleta, transporte de disposição final que viabilizem a colocação desse resíduo de construção e demolição reciclados como matéria-prima na composição de novos materiais (DIAS, 2007).

Nesse contexto a maior parte do desperdício desses materiais é de origem mineral: concretos, argamassas, blocos, tijolos, telhas, solos, gesso dentre outros. Diante desse fato, pode-se observar o modelo de construção civil tradicional no Brasil, onde as maiores perdas ocorrem na fase de concretagem, alvenarias, revestimento e acabamento (GEHRKE, 2012).

Percebe-se que a reciclagem se mostra como importante alternativo para a redução da quantidade de resíduos a ser depositados em aterros bem como para diminuir a parcela de matériasprimas necessárias para construção. Alguns resíduos que anteriormente era descartado, hoje já podem ser considerados subprodutos de outras indústrias e são aproveitados como insumos na construção civil. A reciclagem da construção civil é de extrema importância, pois fecha o ciclo de vida dentro do próprio setor, o que gera um equilíbrio entre a oferta de subproduto e demanda (BIGOLIN, 2013).

Nesse caso, a melhoria da reciclagem constitui uma diminuição dos custos de limpeza pública e das obras públicas onde os materiais recicláveis forem utilizados, e, como consequência, melhor aproveitamento das áreas de aterro remanescentes, com a minimização do ritmo de seu esgotamento. O setor da construção civil deve tentar fechar o seu ciclo produtivo, diminuindo a saída de resíduos e a entrada de matéria-prima não renovável (ÂNGULO; ZORDAN; JOHN, 2001).

Portanto, pode-se concluir que a reciclagem possibilita a preservação de recursos naturais com a consequente redução da destruição da paisagem, flora e fauna, e também pode transformar uma fonte de despesas em uma fonte de faturamento, pois reduz custos e gera novas oportunidades de negócios (JADOVSKI, 2005). 


\title{
RCC E OS IMPACTOS AMBIENTAIS
}

Os RCC's no Brasil alcançam altas extensões da massa dos resíduos sólidos urbanos que vão de $51 \%$ a $70 \%$. Isso contraria os princípios do desenvolvimento sustentável, esgotando os recursos naturais e destruindo a paisagem (MANSOUR, 2008). Nesse contexto, pode-se afirmar que uma disposição final em local não adequado, causa impacto ambiental. Quanto à definição para esse termo, a Resolução nº 001 (BRASIL, 1986) apresenta a seguinte redação:

\begin{abstract}
Qualquer alteração das propriedades físicas, químicas e biológicas do meio ambiente, causada por qualquer forma de matéria ou energia resultante das atividades humanas que, direta ou indiretamente, afetam a saúde, a segurança e o bem estar da população, as atividades sociais e econômicas; a biota; as condições estéticas e sanitárias do meio ambiente; e a qualidade dos recursos ambientais. (BRASIL, 1986).
\end{abstract}

Em face dessa definição, percebe-se que novas construções ou reformas em alvenaria, provocam impactos diversos (Ex.: ruído, fluxo intenso de trabalhadores, acúmulo de entulhos) podem criar alguns inconvenientes para as pessoas que moram ou transitam na região onde foram executadas, porém não sendo necessariamente negativos, uma vez que estes podem gerar benefícios ao entorno. Por isso, deve-se sempre levar em consideração a opinião da sociedade quanto a estas intervenções.

Contudo, todas as etapas do processo construtivo causam impactos ambientais, desde a captação da matéria-prima até a demolição, e podem afetar direta e indiretamente, o bem-estar, saúde e segurança da população, as atividades sociais e econômicas, o meio ambiente e os recursos naturais de forma geral (GAEDE, 2008).

Dentro deste cenário, a diversidade de impactos que a construção civil causa ao meio ambiente estabelece matrizes que relacionam três fases distintas, implantação e operação do canteiro de obras, consumo de recursos e por fim incômodos e poluições nos meios físico (solo, ar e água), biótico e antrópico (trabalhador, vizinhança e sociedade) (CARDOSO et al., 2006).

Os bota-foras clandestinos criados pela população local, normalmente de baixa renda, não são usados somente para a deposição dos resíduos de RCC, outros tipos de resíduos também são depositados ali, os não-inertes, volumosos, industriais, urbanos dentre outros, causando um impacto ambiental ainda maior, já que a mistura de vários resíduos irá fazer com que o processo de degradação da área seja mais rápido, diminuindo a possibilidade de uma recuperação futura do local. A ausência da captação desses resíduos traz do mesmo modo impactos sociais, como a obstrução das vias de trânsito, obstrução de calçadas para circulação de pedestres, mau cheiro, poluição visual e o favorecimento da multiplicação de vetores que podem transmitir doenças (PUCCI, 2006).

Nesse contexto, algumas situações impactantes podem ser ocasionadas em longo prazo, como o adensamento populacional e, por isso, deve-se sempre prever equipamentos (como telas para evitar que materiais particulados e pequenos resíduos afetem a vizinhança) urbanos e comunitários para atender a população já residente e também prevendo uma expansão urbana, considerando o uso e ocupação do solo de acordo com o plano diretor e as legislações ambientais daquela região (GAEDE, 2008). As quantidades de RCC produzidas atingem a sociedade em três grandes dimensões (MARQUES NETO, 2009):

a) dimensão econômica: onde se refere aos custos de limpeza pública para remoção e aterramento dos resíduos. Estes serviços são executados pelos órgãos municipais, gerando custos mais elevados;

b) dimensão social: relaciona-se às pessoas que tem a catação como sua única atividade ou forma de sobrevivência, vivendo geralmente no entorno das áreas de deposição;

c) dimensão ambiental: se refere às áreas de disposição clandestina e irregular. Tais áreas, via de regra, são as mais vulneráveis da cidade (córregos, áreas de proteção ambiental áreas de mananciais, entre outras).

Assim, não só o impacto ambiental da cadeia da construção civil no solo ou lençol freático, no ar, sobre a fauna, flora e paisagem, e também sobre o clima, devem ainda ser considerados, mas 
também os impactos não ambientais, como aqueles que afetem o emprego, renda e inclusão, acessibilidade e mesmo segurança e saúde, entre outros (BLUMENSCHEIN, 2004).

\section{MATERIAL E MÉTODOS}

O método empregado foi o hipotético-dedutivo, pois, de acordo com o exposto por Brito (2001) porque se faz da indução para organizar as ideias e defende, em primeiro lugar, o problema e a conjectura a serem testadas na observação. Complementou-se com o método observativo sistemático. Para melhor elaboração do presente estudo, ele foi divido em duas etapas.

A primeira etapa foi o levantamento de dados documentais, para maior entendimento sobre o problema, bem como buscar identificar as principais aplicações e destinações dadas para os resíduos da construção civil.

A segunda etapa da realização do trabalho tratou da coleta de dados, que consistiu no acompanhamento in loco e verificação do processo de geração do resíduo durante a realização da obra pela empresa objeto de estudo. As visitas ao canteiro de obras foram realizadas durante o mês de setembro, sendo a etapa em que se realizou o estudo foi a de fundação, com registros fotográficos.

\section{ÁREA DE ESTUDO}

O Município de Paragominas está localizado no nordeste paraense, e apresenta as seguintes coordenadas geográficas: Latitude Sul $02^{\circ} 59^{\prime} 45^{\prime \prime}$ e Longitude Oeste $47^{\circ} 21^{\prime} 10^{\prime \prime}$. Altitude média de $90 \mathrm{~m}$, distante da capital do estado, Belém, a $320 \mathrm{~km}$ no sentido Belém-Brasília. Limita-se ao Norte com os municípios de Ipixuna do Pará e Nova Esperança do Piriá, a Leste com o estado do Maranhão, ao sul com os municípios de Dom Eliseu, Ulianópolis e Goianésia do Pará e a oeste com município de Ipixuna do Pará (Figura 1).

Figura 1 - Mapa da localização do município de Paragominas - Pará.

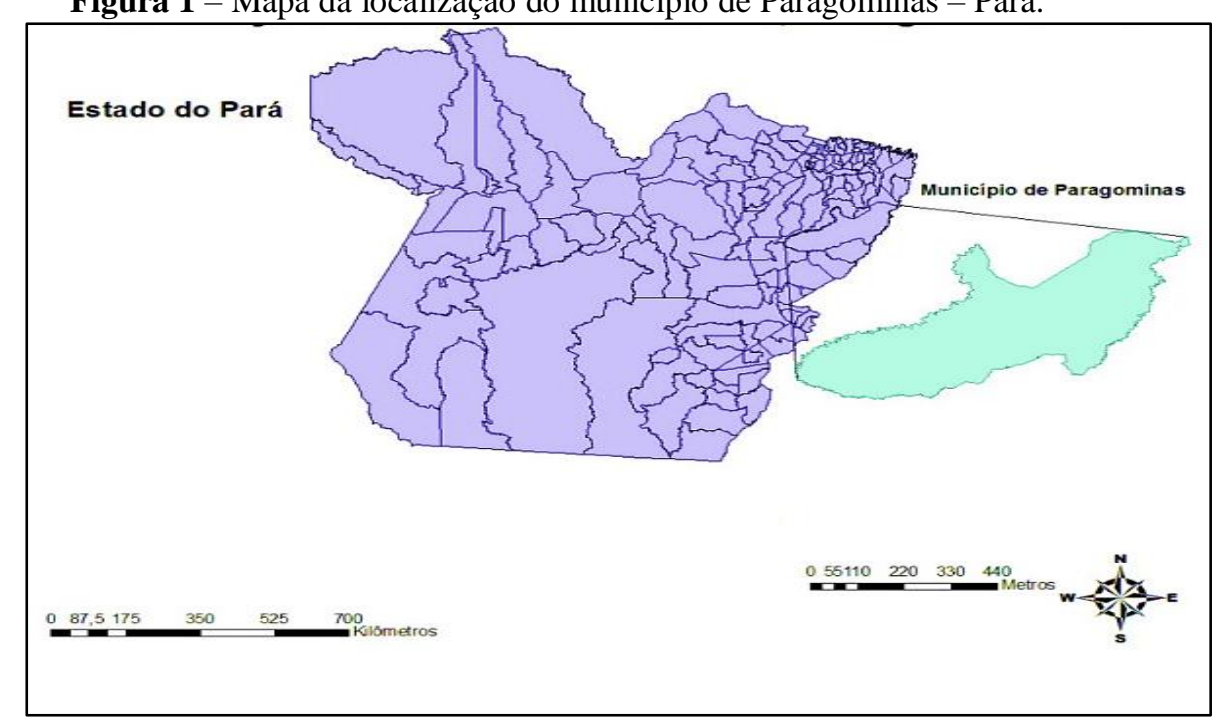

Fonte: Lemos (2013).

De acordo com o último Censo Demográfico, a população da cidade, é estimada em 97.877 habitantes e apresenta um crescimento populacional de 2,82\% ao ano (IBGE, 2010). O clima do município, é classificado como do tipo quente e úmido, com temperatura do ar média anual de $26^{\circ} \mathrm{C}$ e umidade relativa do ar média de $81 \%$, a vegetação predominante é do tipo floresta densa, os tipos de solo são os latossolos amarelo com alto grau de intemperismo, profundos, ácidos e ricos em alumínio, é banhada por duas bacias principais: Capim, que se ramifica sobre $54 \%$ da área do município e a do Gurupi que ocupa os outros $46 \%$ restantes, o relevo possui $35 \%$ do território com 
altitude de 100 e $150 \mathrm{~m}, 35 \%$ entre 50 e $100 \mathrm{~m}, 20 \%$ entre 150 e $200 \mathrm{~m}, 6 \%$ superior a $200 \mathrm{~m}$ e $4 \%$ se encontram em áreas menores que 50m (IMAZON, 2009).

\section{COLETA DE DADOS}

Foram realizados quatros coletas, uma por semana, durante o mês de setembro no canteiro de obras da Empresa x. Para o registro dos dados, as amostras eram realizadas da seguinte maneira, coletou-se os resíduos de forma aleatória, sendo os resíduos pesados 3 vezes para ser retirada a média dos valores obtidos de cada resíduo, foi utilizada uma recipiente plástica com volume igual a 20L, as mesmas foram pesadas em uma balança digital de $150 \mathrm{Kg}$, que pode ser observado na Figura 2, e os resultados encontrados foram transformados $\mathrm{em}^{3}$.

Figura 2 - Balança de $20 \mathrm{~kg}$ utilizada para pesagem do material coletado no canteiro de obras da Empresa X Paragominas - Pará.

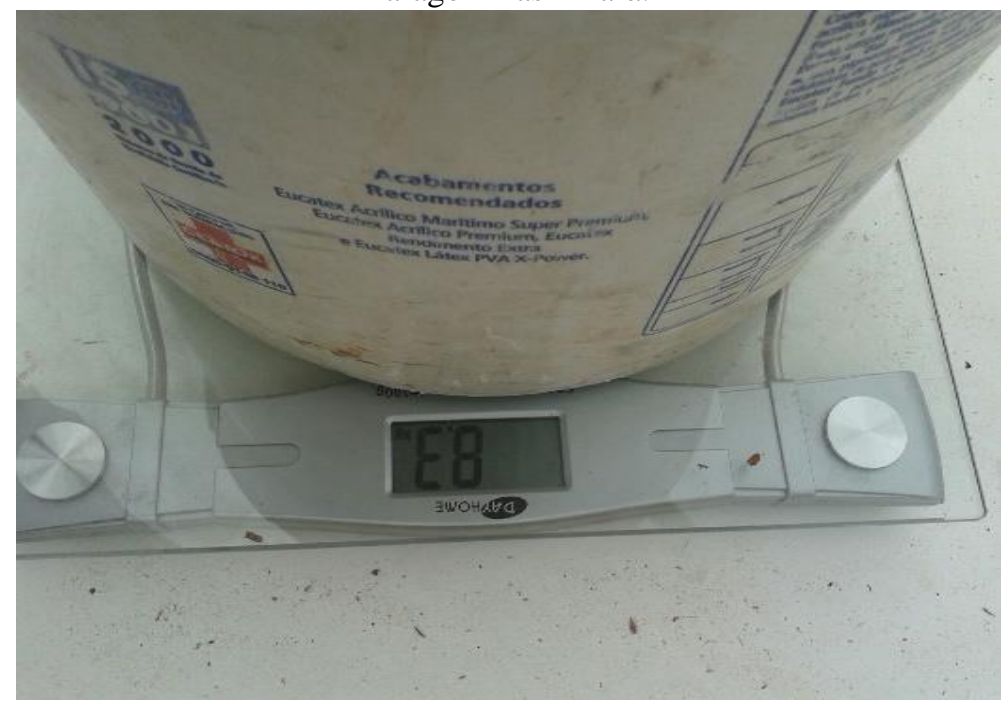

Fonte: autores (2015)

Ao término da coleta de dados da etapa de fundação, lembrando que a densidade obtida foi à aparente, pois não foram levados em consideração os espaços vazios que ficaram no recipiente.

\section{TRATAMENTO ESTATÍSCO DO DADOS}

Os dados obtidos após as coletas foram tratados estatisticamente com o uso de planilhas eletrônicas contida no Excel (2013), com a aplicação da Estatistica Descritiva (frequência relativa), bem como Equações para os cálculos de densidade (Equação 1), volume (Equação 2), porcentagem (Equação 3) e massa, em m³ (Equação 4).

$$
\boldsymbol{d}=\frac{\boldsymbol{m}(\boldsymbol{g})}{\boldsymbol{v}\left(m^{3}\right)}(1)
$$

Onde: $\mathrm{d}$ - densidade; $\mathrm{m}$ - massa; $\mathrm{v}$ - volume 


\section{RESULTADOS E DISCUSSÃO}

\section{FORMA DE REAPROVEITAMENTO DOS RESÍDUOS GERADOS}

Foi verificado que a Empresa em tela reaproveita parte dos resíduos gerados como, por exemplo, a madeira, que representa $80 \mathrm{~m}^{3}(56,6 \%)$ do total de resíduos 141,4 $\mathrm{m}^{3}$ (Tabela 2).

Tabela 2 - Resíduos de Construção de Demolição gerados pela Empresa X Paragominas - PA.

\begin{tabular}{|c|c|c|c|c|c|}
\hline Resíduo & $\mathbf{m}^{3}$ & $\%$ volume & $\% \mathrm{~m}$ & $\begin{array}{l}\text { (Kg) } \\
\text { (Kassa }\end{array}$ & $\begin{array}{l}\text { Densidade } \\
\mathrm{Kg} / \mathrm{m}^{3}\end{array}$ \\
\hline Madeira & 80 & 56,6 & $117201,933,4$ & 28,5 & 1465 \\
\hline Ferro & 5,4 & 3,8 & $22365,9 \quad 6,4$ & 80,7 & 4141,8 \\
\hline Entulho & 48 & 33,9 & $178765,350,9$ & 72,5 & 3724,3 \\
\hline Sucata & 8 & 5,7 & $33080,49,4$ & 80,5 & 4135,1 \\
\hline Total & \multicolumn{2}{|c|}{141,4100} & 351413,4100 & & \\
\hline
\end{tabular}

Fonte: autores (2015)

Pode-se observar que a madeira e o entulho são os que apresentam maiores volumes e massa apresentando 56,6\% e 50,9\% respectivamente do total, já a sucata e o ferro são os que apresentam os menores valores com $5,7 \%$ e $6,4 \%$ respectivamente, trazendo valores muito inferiores que os da madeira e do entulho.

Os dados obtidos e analisados indicaram que a empresa em estudo possui formas de reaproveitamento dos resíduos por ela gerados nos canteiros de obra. Uma dessas formas é efetivada a partir da segregação dos resíduos gerados em seu canteiro de obra, e são separados em 4 tipos: ferro (Figura 3a), madeira (Figura 3b), e sucata (Figura 3c).

Figura 3 - Segregação dos resíduos de construção civil: a) ferro; b) madeira; c) sucatas. Paragominas PA.

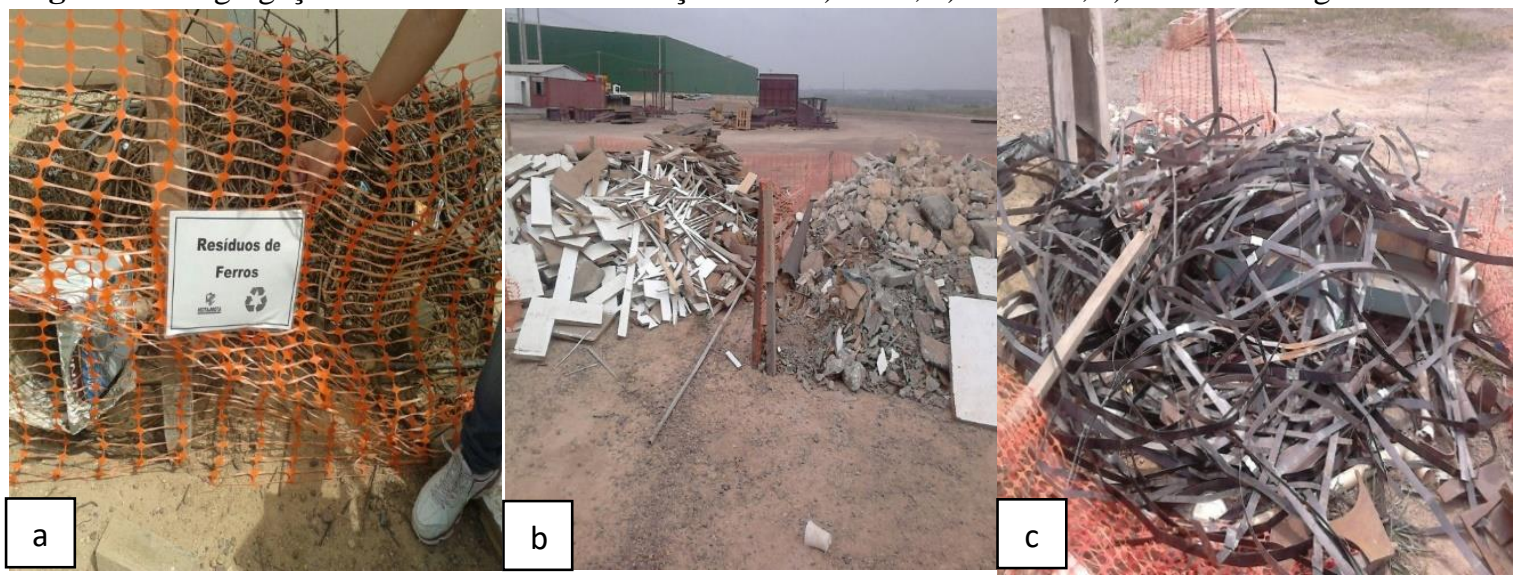

Fonte: autores (2014).

Após a análise dos dados, verificou-se que, de um total de 141,4 $\mathrm{m}^{3}(100 \%)$ de resíduos gerados, a madeira que representa $80 \mathrm{~m}^{3}(56,6 \%)$ é encaminhada para a caldeira da empresa que a utiliza como fonte de energia. O resíduo sucata, que representa $5,4 \mathrm{~m}^{3}(3,8 \%)$, é reutilizado na própria obra, para soldagens dos metais. Em relação ao Ferro e o entulho, que não são reaproveitados dentro da empresa e representam $53,4 \mathrm{~m}^{3}(39,6 \%)$, são encaminhados ao aterro controlado existente no município.

Acerca do reaproveitamento de RCC, Cunha (2005) efetuou estudo em Belo Horizonte - MG, e concluiu que há um nível de reaproveitamento e em torno de $45 \%$ dos resíduos gerados. Nesse contexto, verifica-se que a ação empregada pela empresa em estudo corrobora com os resultados obtidos em Belo Horizonte. Na pesquisa realizada em Paragominas, apenas o reuso da sucata ficou 
abaixo de $30 \%$, e o reaproveitamento da madeira ultrapassou o percentual encontrado em Belo Horizonte. Nesse caso, a empresa pesquisada, está no estágio inicial de reaproveitamento dos RCC's.

\section{REDUÇÃO DE MATERIAIS PARA PRODUÇÃO}

A análise dos dados obtidos indicou que a empresa pesquisada não se preocupa com as perdas de materiais, que pode ir desde erros na hora do projeto, até a execução de tarefas desnecessárias. Isso foi observado quando das visitas efetuadas in loco, percebeu-se o grande desperdiço de material no decorrer das atividades realizadas que teria origem no processo ou execução inadequada dos mesmos, segundo o funcionário responsável pelo setor.

Acerca desse desperdício, foi realizada uma pesquisa no município de Porto Alegre -RS, por Formoso, Cesare e Lantelme (2014), e os dados obtidos indicaram que isso poderia ser evitado, caso a obra possuísse uma política definida de administração de materiais, tanto na aplicação de um controle sistemático para sua utilização, como em relação ao seu gerenciamento. Esses autores também escreveram que fazer o planejamento e controle das perdas desses materiais é essencial para que possa haver uma redução dos materiais e consequentemente do desperdício do mesmo e começa a ser mais utilizado o emprego de materiais recicláveis.

Em Paragominas, devido à negligência quanto ao desperdício fica evidente que a empresa não possui conhecimento da magnitude das perdas acontecidas no canteiro de obra, contrariando o CONAMA 307/02, artigo $2^{\circ}$, inciso $\mathrm{V}$, que dispõe sobre o gerenciamento de resíduos que visa a redução, reutilização e reciclagem dos resíduos para desenvolver e implementar ações necessárias ao cumprimento das etapas previstas nos programas e planos da empresa.

\section{CONTROLE, ARMAZENAMENTO, TRANSPORTES E DEGRADAÇÃO DOS MATERIAIS.}

Quanto a matéria prima que é utilizada no canteiro de obras, os dados obtidos indicaram que ele chega através das empresas que forneceram a mesma, posteriormente são encaminhados para o almoxarifado da empresa onde ficam estocadas, porém, a mesma não possui controle da saída desse material, ou seja, não tem conhecimento dos gastos dessas matérias, assim não regula suas perdas.

Em relação ao controle, armazenamento, transporte e degradação de materiais, Almeida Júnior (2000), efetuou um estudo em Taubaté - SP, sobre a recepção controle e estocagem de materiais de construção, e afirmou que essas medidas administrativas devem ser itens obrigatórios no Plano de Gerenciamento da empresa para verificação dos gastos e mitigação dos custos. Na empresa pesquisada em Paragominas, não há uma Gestão de Materiais. Tal afirmativa prende-se ao fato de que, sem controle da entrada e saída de matéria-prima, isso pode vir a gerar uma superlotação dos almoxarifados ou haver desperdício de materiais, já que a falta da administração da quantidade de materiais faz com que não se tenha noção do quanto de material é existente na empresa.

Quanto ao transporte dos materiais foi verificado que é realizado por empresas terceirizadas, onde o material é comprado. Quanto a destinação do resíduo gerado na empresa, o transporte é realizado pela mesma, através de caminhão, entretanto, não tem dia fixo de coleta desses resíduos, sendo que a maior frequência de coleta é uma vez por semana, sem um dia fixo para a realização da atividade, e quanto a destinação do mesmo, segundo o funcionário da empresa, todos os resíduos que não são encaminhados para a caldeira são dispostos no aterro controlado do município.

\section{CONCLUSÃO}

A necessidade de que seja implantado um plano de gerenciamento de resíduos de construção na empresa pesquisa, para a diminuição da geração dos RCC's, até a disposição final, para ela não ocorra em locais inapropriados, além de proporcionar reciclagem desses resíduos, que pode ser 
executada dentro do canteiro de obras, para assim poder mitigar a quantidade de matéria prima utilizada e reduzir a sua extração. Logo, o desequilíbrio causado por inexistência de ações que mantenham a harmonia ambiental, necessita urgentemente de ações importantes para incentivar a implantação de diretrizes municipais que permeiem tais ações.

\section{SUGESTÕES}

Recomenda-se que a partir da realização dessa pesquisa, as construtoras saibam e assumam suas responsabilidades como geradora de RCC's seja de pequeno, médio ou grande porte, além de fazer o plano de Gerenciamento de Resíduo de Construção Civil e executando-o, dando o município subsídios que apoiem e incentive tais iniciativas, e o principal, que Paragominas saia da inércia e crie um local para destinação adequada de seus resíduos e é preciso uma fiscalização mais atuante dos órgãos ambientais fazendo-se mais presente para que seja comprido as determinações da leis.

Torna-se necessário realizar uma gestão integrada desses resíduos que irá trazer benéficos na área ambiental, social e econômica. Deverá ser feito também uma mudança de hábitos dentro da empresa que deve ir desde o operário até o dono da empresa, começando pela conscientização e sensibilização ambiental, importância do gerenciamento desses resíduos, o porquê desse gerenciamento dentre outras.

É imprescindível que seja feita a fiscalização no canteiro de obra, educação ambiental, capacitação de todos os funcionários da empresa relacionado ao gerenciamento de RCC com o intuito de alcançar metas de não geração, minimização, reciclagem, reutilização e segregação dos resíduos desde o início da obra, com o manejo apropriado dos resíduos dentro do local de trabalho, para posteriormente ser realizado o recolhimento e levado ao local apropriado e licenciado. São ações que possuem um caráter de fundamental importância para que os RCC's tenham sua destinação final correta.

\section{REFERENCIAS}

ABNT. ASSOCIAÇÃO BRASILEIRA DE NORMAS TÉCNICAS.NBR - 10.004:Resíduos Sólidos: Classificação. Rio de Janeiro: novembro, 2004. Disponível em: $<$ http://www.aslaa.com.br/legislacoes/NBR\%20n\%2010004-2004.pdf >. Acesso em: 29 set. 2014.

ANJOS. H. M. 2014. Foto Coleção particular.

ALMEIDA JUNIOR, L. A. O gerenciamento do suprimento, manuseio e armazenamento na construção civil. 2000. Monografias (Graduação em MBA - Gerência Empresarial).Universidade de Taubaté, São Paulo, 2000.

A importância da construção civil. Mazanto, Rio Grande do Sul, 13 mar. 2014. Disponível em: <http://www.manzato.com.br/pt-br/noticias/a-importancia-da-construcao-civil-61>. Acesso em: 30 set. 2014.

ÂNGULO, S. C. et al. Metodologia de caracterização de resíduos de construção e demolição. In: VI Seminário de Desenvolvimento Sustentável e Reciclagem na Construção Civil. IBRACON CT-206. São Paulo, 2003.

ÂNGULO, S. C.; ZORDAN, S. E.; JOHN, V. M. Desenvolvimento sustentável e a reciclagem de resíduos na construção civil. In: Seminário Desenvolvimento Sustentável e a Reciclagem na construção civil, 4, 2001-materiais reciclados e suas aplicações. CT206-IBRACON. São Paulo, 2001. 
AQUINO, M. D. et al. Proposta de Gestão Sustentável dos Resíduos Sólidos da Construção Civil no Município de Fortaleza. In: $23^{\circ}$ Congresso Brasileiro de Engenharia Ambiental e Sanitária. 2004. Disponível em<http://www.bvsde.paho.org/bvsacd/abes23/III-100.pdf> Acesso em: 7 ago. 2014.

AZEVEDO, G. O. D. A; KIPERSTOK, A; MORAES, L. R. S. resíduo da construção civil em Salvador: os caminhos para uma gestão sustentável. [sol.], 2006.

BARBOSA, J. Destinação dos resíduos sólidos de construção e demolição do Município de Passo Fundo- RS: Desafios e Perspectivas. Monografia apresentada ao Curso de Engenharia Ambiental; Universidade de Passo Fundo, Rio Grande do Sul, 2012.

BLUMENSCHEIN, R. N. A sustentabilidade na cadeia produtiva da indústria da construção. 2004. Tese (Doutorado em Engenharia Civil). Universidade de Brasília, Brasília-DF, 2004.

BRASIL. CONSELHO NACIONAL DO MEIO AMBIENTE. Resolução CONAMA nº 307, de 5 jul. 2002. Diário Oficial [da] República Federativa do Brasil, Brasília-DF. Disponível em:<http://www.cetesb.sp.gov.br/Agua/praias/res_conama_357_05.pdf>. Acesso em: 07 out. 2014.

BRASIL. Lei $\mathbf{n}^{\circ}$ 12.305, de 2 de agosto de 2010. Política Nacional de Resíduos Sólidos. 2010. Disponível em:<http://www.mma.gov.br/port/conama/legiabre.cfm?codlegi=636>.Acesso em: 23 jun. 2014.

BRASIL. CONSELHO NACIONAL DO MEIO AMBIENTE. Resolução CONAMA nº 001, de 23 jan. 1986. Diário Oficial [da] República Federativa do Brasil, Brasília, DF. Disponível em: <http://www.mma.gov.br/port/conama/res/res86/res0186.html >. Acesso em: 03 ago. 2014.

BRITO, A. Metodologia científica, Paraná: Pontífice Universidade Católica, 2001. Disponível em: <http://www.ppgia.pucpr.br/ alceu/mestrado/MC/MCIC_01_v3.pdf>. Acesso em: 25 out. 2014.

CARDOSO, F. F. et al. Impactos ambientais dos canteiros de obra: uma preocupação que vai além dos resíduos, In: XI ENCONTRO NACIONAL DE TECNOLOGIA DO AMBIENTE CONSTRUIDO. Anais XI ENCONTRO NACIONAL DE TECNOLOGIA DO AMBIENTE CONSTRUIDO. Florianópolis 2006, p. 3550-3559.

CARDOSO, W. Construção Civil no Brasil. Engenharia e, [s.1.], 2013. Disponível em: <http://www.engenhariae.com.br/colunas/construcao-civil-no-brasil/>. Acesso em: 01 out. 2014.

CARNEIRO, F P. Diagnóstico e ações da atual situação dos resíduos de construção e demolição na cidade do Recife. 2005. Dissertação (Mestrado). Universidade Federal da Paraíba, João Pessoa, 2005.

CASTRO, F. A força e a importância da construção civil na economia brasileira. Dzai, 2012. Disponível em: <http://www.dzai.com.br/franciscocastro/noticia/montanoticia?tv_ntc_id=66538>. Acesso em: 10 out. 2014.

CUNHA, J. N. Cartilha de Gerenciamento de Resíduos Sólidos para Construção Civil. Belo Horizonte (MG): Brasil.2005.

DIAS, E. C. M. Gerenciamento de resíduos na construção civil. São Paulo - SP. 2007. Monografia (Trabalho de Conclusão de Curso) - Universidade Anhembi Morumbi. 2007. 
ERDEI, L. F. T. Importância da Construção Civil para a Economia do Brasil. Salário mínimo, [s.l.]. 2011. Disponível em: <http://www.salariominimo.net/2011/02/21/importancia-da-construcao-civilpara-a-economia-do-brasil/>. Acesso em: 01 out. 2014.

FERNADES, M. P. M. Apreciação de boas práticas visando a geração de um modelo para a gestão municipal dos resíduos da construção civil. 2013. Tese (Doutorado em Engenharia Civil). Universidade Federal do Rio Grande do Sul, Porto Alegre, 2013.

FORMOSO, C. T.; CESARE, C. M.; LANTELME, E. M. V. As perdas na construção civil: conceitos, classificações e seu papel na melhoria do setor. UFRGS, Rio Grande do Sul, 2000. Disponível em: 〈http://www.pedrasul.com.br/artigos/perdas.pdf>. Acesso em: 25 set. 2014.

FRAGA, M. F. Panorama da geração de resíduo da construção civil em Belo Horizonte: medidas de minimização com base em projeto e planejamento de obras. 2006. Dissertação (Mestrado em Saneamento, Meio Ambiente e Recurso Hídricos) - Universidade de Minas Gerais, Belo Horizonte, 2006.

GAEDE, L.P. F. Gestão dos resíduos da construção civil no município de Vitória - ES e normas existentes. 2008. Monografia (Graduação em Especialização em construção civil). Universidade federal de Minas Gerais, 2008.

GEHLEN, J. Construção da Sustentabilidade em Canteiros de Obras - Um estudo DF. 2008. Dissertação (Mestrado em Arquitetura e Urbanismo) - Universidade de Brasília, Brasília, 2008.

GEHRKE, A. E. B. Indicadores de Sustentabilidade como Ferramenta de Apoio a Gestão Pública de Resíduos da Construção Civil em Município de Pequeno Porte. 2012. Dissertação (Mestrado em Engenharia); Universidade do Rio Grande do Sul, Porto Alegre, 2012.

HOOD, R. S. S. Análise da viabilidade técnica da utilização de resíduos de construção e demolição como agregado miúdo reciclado na confecção de blocos de concreto para pavimentação. 2006. Dissertação (Mestrado em Engenharia Civil). Universidade Federal do Rio Grande do Sul, Porto Alegre, 2006.

IBGE. INSTITUTO BRASILEIRO DE GEOGRAFIA E ESTATÍSTICA. Censo Demográfico 2010. Disponível em <www.ibge.gov.br/catálogos/indicadores>. Acesso em 10 out. 2014.

IMAZON. INSTITUTO HOMEM DA AMAZÔNIA. Diagnóstico socioeconômico e florestal do município de Paragominas. Belém, 2009.

IPEA. INSTITUTO DE PESQUISA ECONÔMICA APLICADA. Diagnóstico dos resíduos sólidos da construção civil. Brasília, 2012.

JADOVSKI, I. Diretrizes técnicas e econômicas para usinas de reciclagem de resíduos de construção e demolição. 2005. Dissertação (Mestrado em Engenharia). Universidade Federal do Rio Grande do Sul, Porto Alegre, 2005.

LOPES, A. F.; CASAGRANDE JUNIOR, E. F. A importância do Plano de Gerenciamento dos Resíduos da Construção Civil (PGRCC) para a proteção ambiental e segurança do trabalhador em obras: Estudo de caso da cidade de Curitiba. In: V ENCONTRO NACIONAL E III ENCONTRO LATINO-AMERICANO SOBRE EDIFICAÇÕES E CCOMUNIDADE SUSTENTÁVEIS, 2009, Recife, 28 out., 2008. p.1-8. 
MANSOUR, E. D. Gestão de resíduos da construção civil no município de Fortaleza - CE. 2008. Monografia (Graduação em Direito Ambiental). Universidade Estadual do Ceará, Fortaleza, 2008.

MMA. MINISTÉRIO DO MEIO AMBIENTE. Manejo e gestão de resíduo da construção civil. Brasília, 2005.

MARQUES NETO, J. C. Estudo da gestão municipal dos resíduos de construção e demolição na bacia hidrográfica do turvo grande. São Carlos - SP, 2009. Tese (Doutorado) - Universidade de São Paulo, 2009.

MENDES, C. F. Paisagem Urbana: uma mídia redescoberta. São Paulo. Senac. São Paulo, 2009.

OLIVEIRA, E. G.; MENDES, O. Gerenciamento de Resíduo da Construção Civil e Demolição: Estudo de Caso da Resolução 307 do CONAMA. 2008. Universidade Católica de Goiás, Goiânia, 2008.

OLIVEIRA, L. N. Coleta seletiva no município de Santa Maria (RS): Panorama, limitações e oportunidades. 2012. Dissertação (Mestrado em Administração). Universidade Federal do Rio Grande do Sul, Porto Alegre, 2012.

PANDOLFO, F. Proposta de projeto de gerenciamento de resíduo da construção civil para um empreendimento localizado em Porto Alegre. 2012. Monografia (Graduação em Engenharia Civil). Universidade Federal do Rio Grande do Sul, Porto Alegre, 2012.

PAYERAS, D. R. Levantamento dos resíduos sólidos gerados pela personalização não planejada de apartamentos: estudo de caso em Porto Alegre/RS. 2005. Dissertação (Mestrado em Engenharia). Universidade Federal do Rio Grande do Sul, Porto Alegre, 2005.

PINTO, T. P.; GONZALES, J. L. R., (Coord.) Manejo e gestão de resíduos da construção civil. Manual de orientação 1. Como implantar um sistema de manejo e gestão dos resíduos da construção civil nos municípios. Parceria Técnica entre o Ministério das Cidades, Ministérios do Meio Ambiente e Caixa Econômica Federal. Brasília: CAIXA, 2005.

PUCCI, R. B. Logística de Resíduos de Construção Civil Atendendo à Resolução CONAMA 307. 2006. Dissertação (Mestrado em Engenharia) - Universidade de São Paulo, São Paulo, 2006.

RIBEIRO, N. P. Contribuição para uma 'história da construção no Brasil. SIMPÓSIO NACIONAL DE HISTÓRIA, 2011, São Paulo. Anais XXVI- São Paulo: ANPUH, 2011.

SENAC. SERVIÇO NACIONAL DO COMÉRCIO. SENAC e educação ambiental. Rio de Janeiro: Senac, $\quad$ v. $\quad 1, \quad$ n.1, $1992 \quad$-.Disponível em: <http://www.senac.br/informativo/educambiental/EA_022009/EA2_2009.pdf >. Acesso em 20 out 2014.

SOUSA, R. Segunda Revolução Industrial. Revista Brasil Escola, Rio de Janeiro. 2014 Disponível em < http://www.brasilescola.com/historiag/segunda-revolucao-industrial.htm >. Acesso em: 04 set. 2014. 
TÉSIO, P. R. A evolução da engenharia civil no Brasil, nos últimos 100 anos, na construção e restauração de edificações históricas: o caso da estação da luz. 2007. 43 f. Monografia (Graduação em Engenharia Civil). Universidade Anhembi Morumbi, São Paulo, 2007.

UFG. Universidade Federal de Goiás, s/d. Goiás: Labogef. Disponível em: < http://www.labogef.iesa.ufg.br/labogef/arquivos/downloads/metodo_metodologia_19263.pdf $>$.

Acesso em: 25.out, 2014.

UFRJ. UNIVERSIDADE FEDERAL DO RIO DE JANEIRO: história da escola politécnica. Disponível em: < http://www.poli.ufrj.br/politecnica_historia.php>. Acesso em: 30 out. 2014, 2007.

Amanda Campos Pinto

Engenheira Ambiental. camanda00@hotmail.com

Taianaacã Fernandes Brandão Santos

Engenheira Ambiental. taianaacafbsantos@gmail.com

Antônio Pereira Júnior Mestre em Ciências Ambientais Universidade do Estado do Pará. Departamento de Engenharia Ambiental. antonio.junior@uepa.br 